\title{
User Interface Design for Effective E-Learning based on Personality Traits
}

\author{
L. Arockiam \\ Associate Professor \\ Dept. of Computer Science \\ St. Joseph's College (Autonomous) \\ Trichy, TN, India
}

\author{
J. Charles Selvaraj \\ Assistant Professor \\ Dept. of Computer Science \\ A. A. Govt. Arts College \\ Musuri, TN, India
}

\begin{abstract}
E-learning is an emerging discipline in the educational field. The advancement of technology and information age has altered the pedagogy and the ways we learn. Many researchers have shown that E-Learning is one of the means which outshines the traditional learning. Personalized learning and teaching could be regarded as an ultimate level of instruction. The E-learning process is influenced by the human factors and cognitive factors. The main purpose of this paper is to explore the relationship between the personality traits and user interface design parameters. Data on recollection and retention skill were collected through a questionnaire designed. Association rule mining technique was applied on the experimental results and rules were generated. Based on the generated rules, suggestions are made to the interface designer for better UID in E-learning.
\end{abstract}

\section{General Terms}

E- Learning, Association Rule Mining, Human Factor

\section{Keywords}

E-Learning, Personality traits, User Interface Design, Association rule mining

\section{INTRODUCTION}

Web interface studies gain importance due to the fast development and increasing use of the World Wide Web. Web-based learning environments can serve as motivational, instructional, modeling, feedback, and assessment tools to the E-learning process. These environments impact the cognitive and social behaviors of students [1] [2].

Heinström proved that learner's personality influences learning strategies and learning outcomes in real practice [3]. A study of student characteristics and computer-mediated communication revealed that personality may influence academic success in unanticipated ways [4]. Therefore, to achieve the best performance in learning and teaching, especially in self-directed or instructor led E-learning, it is essential to be aware of the learner's aptitude and personality in context.

In the transitional phase to improve traditional modes of teaching, UID in E-learning course management are of high importance in higher education. The significant difference that a digital technology could make necessitated the adherence to guidelines offered by researches for designing technically interactive E-learning environment [5]. The following considerations are intrinsic for implementing Web-based learning materials, which were found to be lacking in many of the developmental approaches:
- integration of the user interface design with human interaction, and

- the evaluation framework to improve the overall quality of Web-based learning environments [6].

The physical organization and material organization of the elearning parameters such as size of text, inclusion of heading; physical layout and size of window also affect the e-learning process [7].

Therefore, there is a need to understand the cognitive factors and human factors of e-learning learners to improve the overall quality of the e-learning. There are various human and cognitive factors involved in the e-learning and they are important for the successful E-learning process.

This paper offers patterns for the designers to design UID based on the correlation between personality traits of students and their respective Recollection \& Retention ability in an Elearning environment.

\section{LITERATURE REVIEW}

The learning contexts have become rich with electronic technologies, and have given way for researches in this development. Many researchers have unraveled to better the efficiency of this medium, taking into considerations its interface quality and cognitive factors.

Haryani Haron in his paper entitled "An Investigation on Predictors of E-Learning", has stated that e-learning is influenced by personality and learning strategy, and moreover the design and accessibility of the E-Learning course material affects the learning process [8].

In a paper published by Yang Ping, he asserts that the recognition of student's knowledge in terms of individual learning style, preferred study habits, learning approach, facilitates the design of E-learning tool [9].

About the use of e-learning interface, Siamak Barzegar in his paper "User Interface in Virtual Learning Environment" declared that the weak interface of UID parameters draws less interest from the students [10].

An experiment conducted by Seto Mulyadi [11] hrough Learning with Process Approach in E-Learning centered on the Personality Development, showed that to produce graduates, who have excellent intellectual giftedness and creative personality could be only achieved if learning was done with process approach within E-learning program.

The Relationship between cognitive style, user personality and perceived multimedia quality was explored by Stephen R. Gulliver, et al from Informatics Research Centre, UK, through 
an experiment on Cognitive style and personality [12]. They showed that personality type and user cognitive style affects information assimilation.

In his research, the author Essaid El Bachari, et al, on Design of an Adaptive E-Learning Model Based on Learner's Personality in the year 2009, proposed a Personalized Education System, which is a learning style matching with learner's preference in online learning education using MyersBriggs Type Indicator's (MBTI) personality dimensions [13].

The E-learning interface design should be a core, integrated component of the overall design of on-line units. The way people learn and the tasks they perform determine the design of an interface and the technological approach has no role in this. In this regard, design layout sites can affect the way students learn and interact on a particular unit [14] [15].

Sweller. J, et al, in their paper "Cognitive architecture and instructional design" arrived that the goal of effective UID is to create an environment for the user to successfully navigate and understand the content of the e-learning course. And that the quality of the UID directly influences the way the learner interacts with and processes the information presented in the UID [16][19].

The paper published by Clark.R.C, et al., "Efficiency in learning: Evidence-based guidelines to manage cognitive load" showed the three major factors that influences the complexity of a UID, namely: (1) cognition, (2) content, and (3) form. These three factors exhibit how individuals perceive a web page, the content that is located at that web page, and the manner in which the web page is constructed [17][18].

Eysenck observed that individual differences could be expressed in terms of just three orthogonal higher order factors: extraversion, neuroticism and psychoticism. He developed Eysenck's Personality Inventory tool to identify the orders [21]. The Eysenck Personality Profiler has been employed in studies concerned with group obsessiveness as a moderator of dissimulation [22], the relationship between personality and intelligence. Personality is a description of consistent emotional, thought and behavioral patterns in a person. And the personality trait is quantified in terms of Extraversion, Neuroticism and Psychoticism. In this paper the Eysenck's Personality Questionnaire, which was revised in the year 2006, is used as a tool to measure the student's personality[20].

Recollection is the retrieval or recall of memory. Retrieval may take the form of recognition, with recall being the higher order tasks because it requires learners to spontaneously remember an item of information rather than merely confirm its previous occurrence. The retrieval process can be increased by providing cues, Stimulant questioning, encouraging the use of external memory aids, etc [23]. Retention is an ability to recall or recognize what has been learned or experienced.

\section{METHODOLOGY}

The experimentation to typecast the students based on the Eysenck's Personality Inventory tool and the abstraction of the characteristics that influence the individuals based on their personality and the insinuation of rules for a User Interface Design, were performed with a batch of 150 students pursuing MCA course. Lucid presentation of the methodology is depicted in Figure 1.

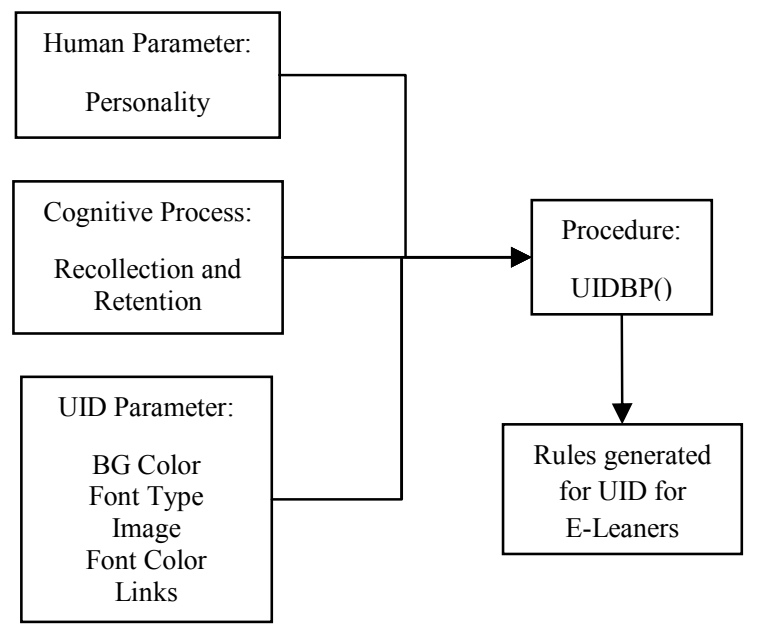

Figure 1 Methodology Diagram

The experiment is designed with the following objectives; to find the existence of any relation between personality traits and $R \& R$ ability in e-learning environment, to isolate the personality types that have a better $R \& R$ ability in e-learning, and to find the influence of User Interface Design in elearning materials with respect to personality traits.

The Recollection and Retention Test is designed based on the Background Color, Font Style and Color, Image used and animations used in the E-learning page. Eysenck's personality test and R\&R test are conducted to all the participants.

From the results of R\&R test and Eysenck's Personality test, the students are further classified based on their interest in color and font style under the three personality traits.

The Procedure below is used to design the UI based on the personality traits with the rules generated from the Association Rule Mining tool.

/*The UIDBP() is invoked to design the User Interface Design based on the Personality traits*/

Start

$\left\{\operatorname{UIDBP}()^{/ *}\right.$ User Interface Design based on Personality traits*/

\{Eyse_PT( ) /*a tool is invoked to retrieve the personality of the students*/

/* based on the personality of the students the following functions are invoked */

\section{If(Extravert)}

\{call Ext_RRP( ) /* Extravert personality preferences are developed through Recollection \& Retention test */ \}

Else if (Neuroticism)

$\{$ call Neu_RRP( ) /* Neuroticism personality preferences are found out through Recollection \& Retention */\}

Else \{call Psy_RRP( ) /* Psychoticism personality preferences are developed through Recollection \& Retention test $* /$ \}

End if

Res_AssoRmin( )/*Personality based Rules are generated*/ 
Gen_of_UIDBP( ) /*Based on generated, rules pages are designed $* /$ \}

\section{Stop}

The following lines decipher the above elementary functions of personality and preferences discovery:

Eysenck has compiled effervescent questionnaires consisting of 42 questions to typecast the personality of the individuals. He organizes the individuals into three different personality traits namely Extraverts, Neurotisms, and Psycotisms. The implementation of the Eysensick's questionnaires is accomplished with the use of the Eyse_PT() function.

On retrieving the findings from the Eyse_PT(), Retrieving and Retention test Ext RRP( ), Neu RRP( ), and Psy_RRP( ), is carried out for Extraverts, Neurotisms, and Psychotisms respectively. The Retrieving and Retention test could be reiterated to identify the eccentric factors influencing the students who are under the Extraverts or Neurotisms or Psychotisms category.

Based on the eccentric factors from the RR test, directives are formed for designing the UID for E-Learners by transferring the findings to the AssoTool(). In succession the Asso_Rules are obtained from the AssoTool(). The suggestions are exported to be used to design the User Interface Design with the invocation of the function Gen_of_ECP().

\section{RESULTS AND DISCUSSIONS}

Based on the Eysenck personality Inventory test, $68.67 \%$, $14 \%, 17.33 \%$ of the students are categorized into three types of personality namely, Extraversion, Neuroticism and Psychoticism respectively as shown in Table 1. Figure 2 shows the graphical representation of the categorization.

Table 1. Personality type among the students' group

\begin{tabular}{|c|c|}
\hline Personality Type & Students (\%) \\
\hline Extraversion & $103(68.67 \%)$ \\
\hline Neuroticism & $21(14 \%)$ \\
\hline Psychoticism & $26(17.33 \%)$ \\
\hline
\end{tabular}

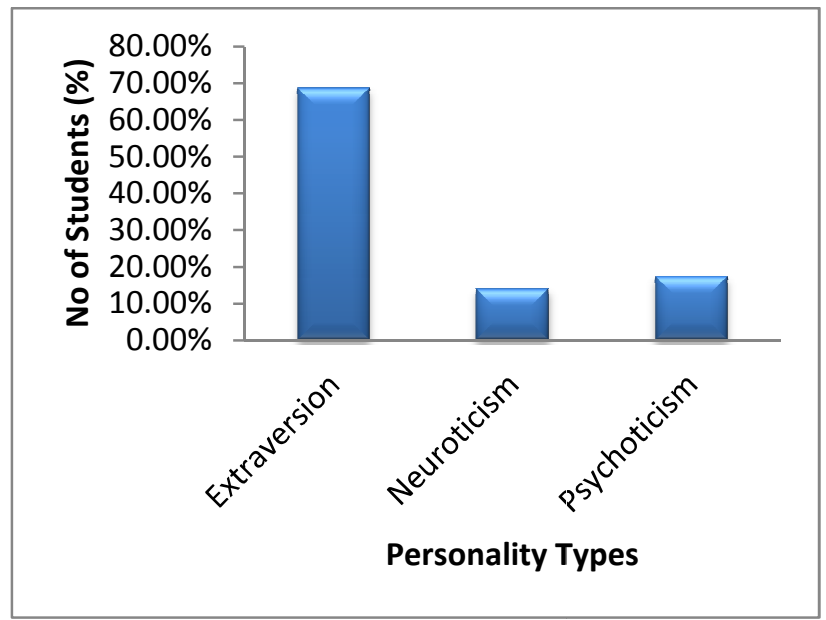

Figure 1. Percentage of the students based on Personality.

\subsection{Types of Relationships between the Personality Traits and UID prameters}

From the results of the R\&R Test, the preferred UID parameters like background color, font type and font color which influence the students are found.

a) Extravert Students:

Table 2. Influencing Color and Font Style of Extravert Students

\begin{tabular}{|c|c|}
\hline Color & Students (\%) \\
\hline Black & $10.67 \%$ \\
\hline Blue & $61.16 \%$ \\
\hline Green & $14.56 \%$ \\
\hline White & $13.59 \%$ \\
\hline Font Style & Students (\%) \\
\hline Arial & $9.71 \%$ \\
\hline Courier & $8.73 \%$ \\
\hline Monotype & $17.48 \%$ \\
\hline Times & $64.07 \%$ \\
\hline
\end{tabular}

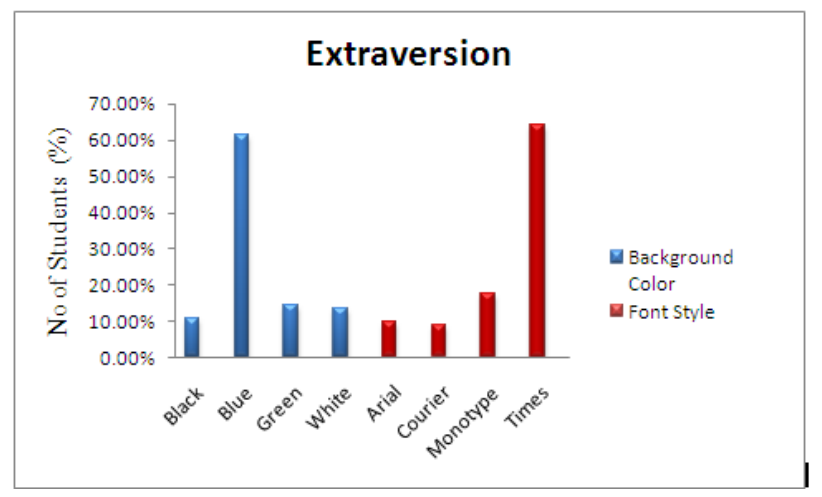

Figure 2. Influencing Color and Font Style of Extravert Students

The result indicates that $61.16 \%$ of the students easily recollect blue color and $64.07 \%$ of the students recollect Times New Roman font style.

\section{b) Psychoticism Students:}

Table 3 shows that the Psychoticism students easily recollect the UID with white color background.

Table 3. Influencing Color and and Font Style of Psychoticism Students

\begin{tabular}{|c|c|}
\hline Color & Students (\%) \\
\hline Black & $15.38 \%$ \\
\hline Blue & $15.38 \%$ \\
\hline Green & $7.69 \%$ \\
\hline White & $61.54 \%$ \\
\hline Font Style & Students (\%) \\
\hline
\end{tabular}




\begin{tabular}{|c|c|}
\hline Arial & $23.08 \%$ \\
\hline Courier & $7.69 \%$ \\
\hline Monotype & $15.38 \%$ \\
\hline Times & $53.88 \%$ \\
\hline
\end{tabular}

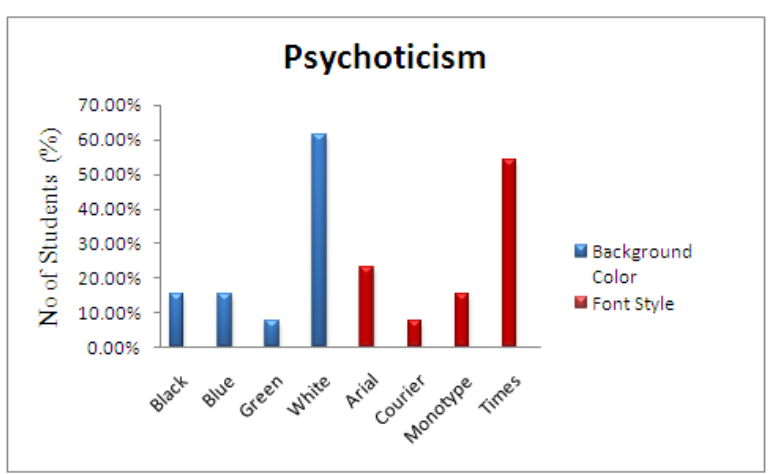

Figure 3. Influencing Color and and Font Style of Psychoticism Students

\section{c) Neuroticism Students:}

Table 4, shows that the Neuroticism students easily recollect the UID with green color background.

Table4. Influencing Color and and Font Style of Neuroticism Students

\begin{tabular}{|c|c|}
\hline Color & Students (\%) \\
\hline Black & $9.59 \%$ \\
\hline Blue & $14.29 \%$ \\
\hline Green & $66.67 \%$ \\
\hline White & $9.52 \%$ \\
\hline Font Style & Students $\mathbf{( \% )}$ \\
\hline Arial & $14.29 \%$ \\
\hline Courier & $9.52 \%$ \\
\hline Monotype & $23.81 \%$ \\
\hline Times & $52.38 \%$ \\
\hline
\end{tabular}

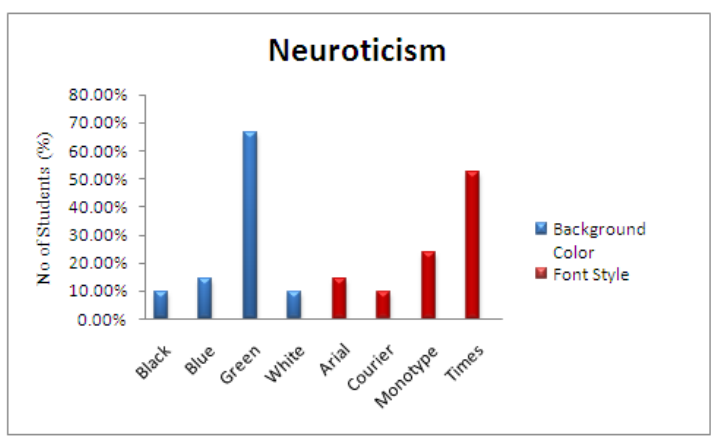

Figure 4. Influencing Color and and Font Style of Neuroticism Students
From the Table 4 it is found that $66.67 \%$ of students recollect White color and $52.38 \%$ of students recollect Times New Roman font style.

d) ARM Rules

The ARM rules are enumerated below:

\begin{tabular}{|c|l|}
\hline Rule 1: & $\begin{array}{l}\text { Extraversion => Font Type ->TimesNewRoman, } \\
\text { BG Color-> Blue Color, Image->like, Font } \\
\text { Color-> White,Active Link ->Red, Visited Link- } \\
\text { >Black. }\end{array}$ \\
\hline Rule 2: & $\begin{array}{l}\text { Neuroticism => Font Type ->TimesNewRoman, } \\
\text { BG Color-> Green Color, Image->like, Font } \\
\text { Color-> Black,Active Link ->Yellow, Visited } \\
\text { Link->White. }\end{array}$ \\
\hline Rule 3: & $\begin{array}{l}\text { Psychoticism => Font Type - } \\
\text { >TimesNewRoman, BG Color-> White Color, } \\
\text { Image->Not like, Font Color-> Black,Active } \\
\text { Link ->Blue, Visited Link->Red }\end{array}$ \\
\hline
\end{tabular}

\section{CONCLUSION}

This paper has proposed a procedure called UIDBP, which provides UID preferences in E-Learning. The findings of the UIDBP are: classification of the students into Extraversion (68.67\%), Neuroticism (14\%) and Psychoticism (17.33\%) from the given sample space, generation of the rules with the use of ARM tool to be used while designing the UID. The generated rules suggest that the students of Extravert personality recollect better when the UID designed with Times New Roman font and blue color background. These rules are validated by conducting the performance test. There is a positive difference in performance of the students while the test is conducted by using the proposed UID rules. The test results show the improvement in the performance of the students.

The correlation between the tests conducted before the UID and with the proposed UID is 0.951 and 0.932 . From the results, it is observed that there is an improvement of $2.01 \%$, which proves that the proposed UID design improves the students' performance.

\section{REFERENCES}

[1] Jannica Heinstrom, "The Impact of Personality and Approaches to Learning on Information Behaviour", Information Research, Vol. 5, No. 3, April 2000,

[2] Shneiderman. B, "Designing the User Interface, 3rd edition”, Addison Wesley Longman, Inc, 1998.

[3] Chen. N. S, and Lin. K. M, "Factors affecting e-learning for achievement", IEEE International Conference on Advanced Learning Technologies, 2002, pp. 9-12.

[4] Mayer. R. E, "Multimedia learning, Cambridge", MA: Cambridge University Press, 2001.

[5] Chien Chou, "Interactivity and interactive functions in web-based learning systems: a technical framework for designers", British Educational Communications and Technology Agency, 2003.

[6] Chang Nam. S, Tonya Smith-Jackson. L, "Web-Based Learning Environment: A Theory-Based Design Process for Development and Evaluation”, 2000. 
[7] Douglas. G and Riding. R. J, "The effect of pupil cognitive style and position of prose passage title on recall”, Educational Psychology, 1993, pp.385-393.

[8] Haryani Haron, and Suriyani Sahar, "An Investigation on Predictors of E-Learing Adoption among Malaysian ELearners", IEEE, 2010.

[9] Yang Ping, Wang Yanni, and Li JinPing, "Study on Personality learning in E-Learning", IEEE, 2009

[10] Siamak Barzegar, Mohammad Shojafar and M.R.Keyvanpour, "User Interface in Virtual Learning Environment”, IEEE, 2009.

[11] Seto Mulyadi, "Intellectual Giftedness and Creative Personality Development through Learning with Process Approach in E-learning Programme", International Journal of Business and Social Science Vol. 2 No. 3, 2011

[12] Stephen R., Gulliver, George Ghinea., "Cognitive style and personality: impact on multimedia perception Online Information Review", University, Uxbridge, UK, Vol: 34,2010 , pp. 39-58.

[13] Essaid El Bachari, El Hassan Abdelwahed, Mohamed El Adnani., "Design Of An Adaptive E-Learning Model Based On Learner's Personality", Cadi Ayyad University .Marrakesh, Vol. 5, No.3, 2009, pp.1-8.

[14] Kenneth Wischmeyer. E, "Designing the E-learning User Interface", White Paper Assignement ITEC 860 fall, 2004.

[15] Matt Germonprez, Ilze Zigurs, "Causal Factors for Web Site Complexity", Vol.3 No. 2, 2005.
[16] Sweller. J, van Merriënboer. J and Paas. F, "Cognitive architecture and instructional design", Educational Psychology Review, 1998, pp.251-296.

[17] Clark. R. C, Nguyen. F and Sweller. J, "Efficiency in learning: Evidence-based guidelines to manage cognitive load”, San Francisco, CA: Wiley, 2006.

[18] Du Jin, Zheng Qinghua, Li Haifei, Yuan Wenbin, "The Research of Mining Association Rules between Personality and Behavior of Learner under Web-Based Learning Environment", Xi'an Jiaotong University, 2005.

[19] Cowan. N, "The magical number 4 in short-term memory: A reconsideration of mental storage capacity", Behavioral and Brain Sciences, 2001, pp. 87-114.

[20] Eysenck. H. J, "A short questionnaire for the measurement of two dimensions of personality", Journal of Applied Psychology, 1958, pp.14-17.

[21] Eysenck. H. J, Barrett. P, Wilson. G and Jackson. C, "Primary trait measurement of the 21 components of the PEN system", European Journal of Psychological Assessment, 1992, pp.109-117.

[22] Jacoby. L. L, "A process dissociation framework: Separating automatic from intentional uses of memory", Journal of Memory and Language, 1991, pp.513-541

[23] Andrew. P, Yonelinas, Larry, Jacoby, "Noncriterial Recollection: Familiarity as Automatic", Irrelevant Recollection, 1996. 